\title{
Téoros
}

Revue de recherche en tourisme

\section{Pour en savoir un peu plus long...}

\section{Jean Pelletier}

Volume 1, numéro 3, 3e trimestre 1982

Les enjeux du tourisme social

URI : https://id.erudit.org/iderudit/1080849ar

DOI : https://doi.org/10.7202/1080849ar

Aller au sommaire du numéro

Éditeur(s)

Université du Québec à Montréal

ISSN

0712-8657 (imprimé)

1923-2705 (numérique)

Découvrir la revue

Citer ce document

Pelletier, J. (1982). Pour en savoir un peu plus long... Téoros, 1(3), 26-26.

https://doi.org/10.7202/1080849ar

Ce document est protégé par la loi sur le droit d'auteur. L'utilisation des services d'Érudit (y compris la reproduction) est assujettie à sa politique d'utilisation que vous pouvez consulter en ligne.

https://apropos.erudit.org/fr/usagers/politique-dutilisation/
Cet article est diffusé et préservé par Érudit.

Érudit est un consortium interuniversitaire sans but lucratif composé de l’Université de Montréal, l'Université Laval et l'Université du Québec à Montréal. Il a pour mission la promotion et la valorisation de la recherche. https://www.erudit.org/fr/ 


\title{
Pour en savoir un peu plus long...
}

\author{
Par Jean Pelletier
}

Le Centre d'Etudes du tourisme met à la disposition des intéressés quelques dizaines de monographies et plusieurs périodiques linformations, courtes analyses et commentaires) traitant des aspects sociaux du tourisme. Nous vous suggérons ici quelques textes récents et disponibles au CET.

Troisgros, S.

Le tourisme social face au développement touristique et aux sociétés multinationales

Bruxelles, Bureau international du tourisme social, novembre 1979, 55 pages.

Au moment où certains pays enregistrent l'impact décevant du tourisme sur le plan économique, et s'efforcent de se consoler en privilegiant la mission culturelle et sociale du tourisme, certains acteurs jadis sacrifiés au nom de considérations purement économiques et financières, rappellent qu'on avait un peu trop vite condamné certaines options. Le B.I.T.S., association internationale pour le développement du tourisme social, rappelle dans un rapport destinè à I'UNESCO que ce tourisme est mieux armé qu'un autre pour assumer les nouvelles fonctions qu'on entend privilégier dans un cadre financier moins couteux.

\section{BITS, \\ Gestion des associations de tourisme social}

Bruxelles, Bureau international du tourisme social, avril 1982, 24 pages.

II s'agit du compte rendu d'un séminaire organisé par le B.I.T.S. et tenu en Italie le 17 avril 1982 . Ce texte rapporte les interrogations et conclusions des participants sur certains aspects les plus difficiles de l'action qui s'impose aujourd'hui aux responsables du tourisme social. Quatre thèmes y sont abordés la mesure des équipements, le fractionnement des vacances, le financement et la responsabilité des gestionnaires. Au cours du débat, il est apparu que si les conditions légales et juridiques dans lesquelles elles agissent sont parfois différentes, il n'en reste pas moins que les organisations sans but lucratif, consacrant leur activité au tourisme social, rencontrent des difficultés similaires, quel que soit le pays où elles se situent.

Nous rappelons également que le Congrès 1980 du BITS s'est tenu au Québec et qu'un volumineux rapport de 752 pages et un condensé de 71 pages sont disponibles au CET sous le titre Tourisme social: besoin nouveau, réponse moderne.
Grosborne, J.-B., Le développement du tourisme social

Rapport au ministre du Temps libre, Paris, La documentation française, janvier 1982 . 91 pages.

Dans le sillage de l'arrivée au pouvoir d'un nouveau gouvernement en France en 1981 et de la création d'un ministère du Temps libre, les autorités politiques ont fait préparer un rapport présentant un constat et un diagnostic de la situation en matière de tourisme social et formulant des propositions pour le plan quinquennal français. L'attention est attirée sur la nécessité absolue, le choix politique une fois fait en faveur du tourisme social, d'une volonté politique claire, puissante et efficace.

$$
\ldots
$$

Nous attirons également l'attention des lecteurs sur quelques publications québécoi= ses récentes qui permettent d'identifier les lignes de force et les contraintes du développement du tourisme social pour les années 80

Ministère du Loisir, de la Chasse et de la Pêche Bilan de la consultation concernant

les possibilités

et conditions

de développement

de la formule Villages-Vacances-Familles (V.V.F.) au Québec

Québec, Gouvernement du Québec, juillet 1982,81 pages.

II s'agit du bilan qui se dégage de la consultation concernant le Rapport du comité conjoint OPDQ-MLCP sur les VillagesVacances-Familles. Le document présente les points fondamentaux de convergence avec le rapport ainsi que les principales réserves (le traitement du réseau et le concept proposé) exprimés dans les avis et mémoires. II est clair qu'une majorité d'intervenants considère préférable une phase d'expérimentation de la formule V.V.F.. notamment du village éclaté, avant toute décision définitive.

\section{Mouvement québécois des camps familiaux,}

Tourisme social projet social Rapport du colloque de mars 1982, Montréal MQCF, (3ième trimestre 1982), 126 pages.

Le document présente les actes d'un colloque tenu à Montréal en mars 1982, colloque qui a voulu générer des collaborations en donnant la parole aux intervenants à la base. Plusieurs thèmes y ont été abordès: femmes et vacances, rôle des syndicats et du mouvement associatif, contrôle populaire de l'aménagement, tourisme urbain alternatif. Les participants ont convenu de l'importance de consolider le mouvement social qui émerge (formation polyvalente et militante, contrôle populaire élargi) et de la nécessité de raffermir l'autonomie et la maturité des groupes.

\section{Samson, Marcel}

en collaboration avec BARNIER, Véronique, Vacances et tourisme 1980

Montréal, INRS-Urbanisation, avril 1982, 161 pages.

Dix ans ont passe depuis la publication d'une première étude de I'I.N.R.S sur les comportements et les aspirations des ménages de la région métropolitaine de Montréal en matière de vacances et de tourisme. Qu'en est-il aujourd'hui de ces comportements? Les inégalités sociales et culturelles relevées en 1970 , subsistent-elles en 1980 ? Les hypothèses émises lors de la première recherche sont-elles encore valables? De nouvelles tendances se sont-elles dessinées? Apporter des éléments de réponse à la question cruciale de l'accessibilité aux vacances tout en rafraichissant et un élargissant les données, tel est l'un des objectifs de cette étude; en s'intéressant aux non-vacanciers -prés de $30 \%$ de la population-, les auteurs cherchent à savoir si le droit aux vacances appartient encore au domaine du rêve pour un certain nombre de personnes. Par ailleurs, cette étude aborde le comportement touristique des Montréalais, cherchant à déterminer de quelle façon ils passent leurs vacances. Autre moment intensif de loisir, le week-end a aussi été considéré, sous l'angle des déplacements touristiques de plus courte durée. L'analyse porte également sur le moment et la durée des vacances, introduisant la question de l'étalement des vacances, qui s'inscrit dans la problématique de l'aménagement du temps. (Le no 2 de Téoros deuxièmetrimestre 1982 contient un résumé des résultats de cette recherche, p.19). 